\title{
DE FÃ PARA FÃ: AS TRADUÇÕES DE CHRONO TRIGGER
}

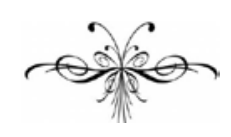

RAFAEL MÜLLER GALHARDI

Resumo: Este trabalho foi desenvolvido sob as perspectivas dos Estudos de Tradução em geral e das traduções de fãs em particular. Através da análise das traducões ao português do Brasil do jogo Chrono Trigger feitas por fãs, foi possível demonstrar como eles chegaram a resultados similares aos produzidos por profissionais da indústria de localização. Para definir os objetos da análise, foram priorizados teóricos que abordam o fenômeno da tradução desde um ponto de vista cultural, como Nord (1994), Newmark (1998), Vermeer (1987) e Fish (1980), além de ser destacado o conceito de "transcriação" utilizado por Mangiron e O’Hagan (2006). O recorte de termos culturais - ainda que de um universo ficcional - permitiu a investigação dos aspectos da tradução que colocam em maior evidência o choque entre duas ou mais culturas. Com esse intento, utilizou-se uma adaptação da proposta de Venuti (1995) a respeito de como traduzir um texto culturalmente marcado em conjunto com as técnicas de tradução sugeridas por Molina e Hurtado (2002). A partir daí, foram analisados os nomes dos personagens em Chrono Trigger nas traduções de dois grupos de fãs: CBT e Ips Center.

Palavras-chave: Videogames. Localização. Tradução de fãs. Transcriação. Chrono Trigger.

\begin{abstract}
This paper was written under the umbrella of Translation Studies in general and of fan translation and game translation in particular. Through the analysis of the translation into Brazilian Portguese made by fans of the game Chrono Trigger it was possible to show how fans may get results similar to those achieved by localization professionals. In order to define the object of our analysis we prioritized a cultural approach to translation following authors such as Nord (1994), Newmark (1998), Vermeer (1987) and Fish (1980). We have also used the concept of "transcreation" as employed by Mangiron and O'Hagan (2006). The selection of cultural terms from the game - despite it being a fictional universe - allowed for the investigation of aspects of those translations that highlight the clash of two or more different cultures. With that in mind, an adaptation of Venuti's translation proposal (1995) on how to translate cultural marked texts was used, along with the translation techniques suggested by Molina and Hurtado (2002). The names of the characters in Chrono Trigger were then analyzed in the translation of two groups of fans: CBT and Ips Center.
\end{abstract}

Keywords: Videogames. Localization. Fan translation. Transcreation. Chrono Trigger. 


\section{Transcriação}

transcriação de videogames envolve a modificação de aspectos
culturais nele presentes de forma a torná-lo mais atrativo para o
local em que será distribuído. Isto pode significar a modificação de características físicas, psicológicas ou discursivas dos personagens e de diversos outros conteúdos multimodais, de forma a tornar mais natural a sua identificação com o público-alvo do jogo. A transcriação requer, portanto, uma participação ativa do tradutor em diversas escolhas que podem influir decisivamente no sucesso (comercial) de um jogo. Nesse sentido, ela assume um caráter análogo ao do conceito de domesticação (VENUTI, 1995), isto é, a supressão de marcas de estranhamento e a adaptação de um determinado produto com elementos da cultura-alvo onde tal produto será disseminado.

De acordo com O’Hagan e Mangiron (2006, p. 17-19), alguns dos aspectos que mais se destacam no processo de transcriação de videogames do japonês para o inglês nas traduções oficiais são: a) a mudança de terminologias essenciais (como nomes de armas, itens e objetos); b) a alteração de nomes de personagens; c) a contextualização por adição; d) a recriação de jogos de palavras; e e) o uso deliberado de expressões informais ou regionais.

Os nomes de itens, objetos e armas tem um papel funcional nos jogos, isto é, permitem que o jogador avance para um nível superior ou supere um desafio. Muitos desses nomes fazem alusões culturais, como, por exemplo, "a espada Masamune” em Chrono Trigger, cujo nome remete a Gorō Nyūdō Masamune, o mais famoso ferreiro de espadas japonês. ${ }^{1} \mathrm{Na}$ tradução desse jogo, algumas dessas alusões são mantidas, porém, no caso específico da conversão para a língua inglesa, uma tradução literal não se mostra possível devido a uma questão de espaço - um kanji (ideograma japonês que pode representar diversos elementos) pode se transformar em uma palavra de seis sílabas, inviabilizando a tradução para o inglês de três kanjis seguidos.

Os nomes de personagens, por sua vez, variam. Alguns fãs preferem ter os nomes traduzidos, enquanto outros preferem a manutenção dos nomes originais ainda que isso possa causar um certo estranhamento no público receptor. Nas traduções oficiais, a prática tradicional nesse caso consiste em suprimir os elementos estrangeiros, substituindo-os por nomes locais.

A “contextualização por adição” diz respeito à necessidade de enfatizar um determinado contexto ou cena de um jogo, de forma que seu impacto emocional seja percebido pelo jogador. O’Hagan e Mangiron (2006, p. 18) citam o caso em que Yuna, personagem do jogo Final Fantasy X (2001), se despede de Tidus, o amor de sua vida. Em japonês, a despedida se dá apenas por um agradecimento como "obrigado". Porém, a tradução ao inglês incorpora a frase "I Love you [eu te amo]" como forma de representar uma atitude e valores culturais típicos do Ocidente.

Ainda segundo Mangiron e O’Hagan, a recriação de jogos de palavras, assim como o uso deliberado de expressões informais ou regionais, justifica-se pela necessidade de um jogo de apresentar uma linguagem que seja de fácil assimilação para o jogador, que o mantenha entretido por diversas horas, uma vez que muitos jogos levam cerca de $30 \mathrm{~h}$ a $40 \mathrm{~h}$ para serem completados. É importante ressaltar que

${ }^{1}$ Fonte: <http://en.wikipedia.org/wiki/Masamune> 
a maior parte das alterações linguísticas e visuais feitas na localização de videogames se deve ao fato de que a função primordial de um jogo é o entretenimento do usuário (MANGIRON; O’HAGAN, 2006, p. 12).

Há uma série de elementos que podem necessitar da intervenção do tradutor, como a interface do jogo, mensagens de erro, dublagens e legendas de vídeo ou áudio, arquivos de informação ao jogador, arquivos de ajuda, guias de instalação (no caso de jogos de computador), mapas, dentre outros. Cada um desses itens varia de acordo com o gênero do jogo, o que influencia o nível de liberdade que o tradutor possui para alterar seus elementos. Um jogo de realismo histórico, como Age of Empires III (2005), ou um jogo que envolva diversas terminologias de equipamentos de guerra, como Battlefield 2 (2005), em princípio, permitem alterações menores do que um jogo baseado em fantasia e que se passa num universo fictício, como Starcraft II: Wings of liberty (2010) ou Chrono Trigger (1995).

É possível utilizar o conceito de "culturalização" de Kersten, Kersten e Rakowski (2002, p. 11) para compreender melhor o fenômeno da "transcriação" - a saber, trata-se da estreita relação que se estabelece entre o usuário de um software e a cultura na qual esse se insere ${ }^{2}$. Assim, quando se considera a produção de um software - e um videogame é antes de tudo um software -, no momento de levá-lo ao mercado internacional não basta localizar apenas sua interface, pois sua funcionalidade como um todo estará intimamente ligada à cultura no seio da qual será utilizado.

No que se refere aos videogames, o processo de "transcriação" é, desse modo, de grande relevância para seu desenvolvimento, uma vez considerado o crescimento da utilização do modelo $\operatorname{sim}_{-}$ship $^{3}$, em que o trabalho do tradutor se dá com um produto não-finalizado, com um material que vai sendo composto à medida que relatórios de erros e de testes de jogabilidade, e diversos outros procedimentos, são realizados - e cujas possibilidades de modificação são limitados por eventuais restrições de tempo e de orçamento.

Traduzir conteúdos culturais é, portanto, muito mais do que simplesmente converter palavras utilizadas em um local para palavras utilizadas noutro, especialmente quando se pretende estabelecer empatia com os jogadores da cultura alvo, ou mesmo evitar problemas legais. Quanto a isso, Dietz (2006, p. 130) cita o caso do jogo Command and Conquer (1995) na Alemanha, cujos inimigos humanos foram transformados em robôs para que o jogo pudesse ser vendido conforme a lei desse país. Esse tipo de intervenção, no entanto, gera diversas reações de protesto por parte de fãs, o que os leva a desenvolver os chamados bloodpatches, isto é, programas que revertem modificações realizadas em um jogo por seu fabricante, como a supressão de elementos de violência ou de cunho sexual.

Assim, na "transcriação" os tradutores têm maior liberdade de adaptar os diferentes elementos que compõem o texto de partida no texto alvo, como seu estilo, tom, expressões idiomáticas, e etc. O objetivo, no caso, é produzir um produto que se comunique mais clara e diretamente, e seja mais bem aceito por seu públicoalvo, em todos os aspectos imagináveis - o que não significa que haja um consenso por parte do público receptor potencial em relação à extensão ou conteúdo de tais

\footnotetext{
${ }^{2}$ A exemplo do fenômeno do "zap-zap" no Brasil - maneira informal de referir-se ao software de smartphone Whatsapp - que tem transformado as relações interpessoais.

${ }^{3}$ Simultaneous shippment, ou seja, lançamento simultâneo em diversos locais.
} 
mudanças, ainda que se as considere fundamentais para uma relação funcional entre o jogador e a tradução.

\section{Marcadores culturais}

O conceito de "cultura" pode ser abordado a partir de diversas perspectivas uma vez que não há um consenso definitivo sobre seu conteúdo nocional. Dentre os pesquisadores dos Estudos da Tradução, Peter Newmark é um dos que se aventuraram a definir cultura: "a maneira de viver e suas manifestações que são peculiares a uma comunidade que usa uma linguagem em particular como forma de expressão" (1988, p. 94). ${ }^{4}$

Outra definição é dada por Hans Vermeer, para quem cultura é “o conjunto de normas e convenções que um indivíduo, como membro de sua sociedade, precisa conhecer de modo a 'ser como todos os outros' - ou ter a capacidade de se diferenciar de todos os demais."

Newmark enfatiza o conceito de cultura destacando o estilo de vida e os costumes de uma comunidade linguística, enquanto Vermeer se baseia em um aspecto social que depende das características e normas de comportamento de membros de uma sociedade. Ao unir as reflexões de ambos, é possível ter me mente uma noção mais ampla de cultura: inclui um sistema de crenças, valores e estratégias por meio dos quais funciona uma comunidade lingüística, e que se regula por normas e convenções que se originam da própria comunidade e afetam todos os seus membros.

Fish (1980) refere-se a essas “comunidades lingüísticas” como “comunidades interpretativas", enfatizando o papel substancial que exercem ao determinar os limites em que é possível apreender determinados significados de uma sentença. Segundo ele, a "comunicação ocorre mesmo na ausência de um sistema de significados independente e livre de contextos” (FISH, 321, 1980) ${ }^{6}$, pois as pessoas, ao participarem de uma comunicação, trazem consigo crenças e idiossincrasias convencionais e comuns aos demais membros de sua própria cultura.

Mayoral (1994) utiliza o termo "marcador cultural” para classificar aquelas palavras ou expressões que revelam um choque entre duas culturas diversas, isto é, quando as convenções e significados de uma cultura não encontram uma correspondência direta na cultura do outro. $\mathrm{O}$ autor defende que esses marcadores podem conferir um sabor local a um texto, contribuindo para sua rede de significação: “Os marcadores espaço-temporais ou culturais servem para dar um maior colorido e expressividade a uma história” (MAYORAL, 1994, p. 87) ${ }^{7}$.

\footnotetext{
4 "the way of life and its manifestations that are peculiar to a community that uses a particular language as its means of expression.” (NEWMARK, 1988, p. 94). Nota: todas as traduções de excertos de obras estrangeiras foram realizadas por mim.

5 "the setting of norms and conventions an individual as a member of his society must know in order to 'be like everybody' - or to be able to be different from everybody.” (VERMEER, 1987:28)

6 "communication does occur, despite of the absence of an independent and context-free system of meanings” (FISH, 321, 1980)

7 "Los marcadores espacio temporales o culturales sirven para dar mayor colorido y expresividad a una historia” (MAYORAL, 1994, p. 87)
} 
No artigo "It's tea-time in Wonderland: culture-markers in fictional texts" (1994), Christiane Nord também utiliza o termo para analisar a função e o tratamento de textos literários nas diversas traduções de duas obras de Lewis Caroll: Alice in Wonderland (1865) e Through the looking glass, and What Alice found there (1871). Nord classifica esses marcadores como referências explícitas ou implícitas que perpassam um texto literário e que indicam ao leitor em qual cultura se passa uma história:

A fim de dar uma pista ao receptor, o "mundo textual” pode ser marcado como pertencendo a uma determinada cultura seja por meio de referências explícitas a um modelo específico da realidade (ex: “onde quer que você vá na costa ingle$s a$ ”) ou por referências implícitas a ações, atitudes, formas de comportamento ou elementos que estão convencionalmente associados a modelos específicos da realidade (ex: um nome próprio como Bill apontando para um mundo textual anglófono). Essas referências explícitas ou implícitas, que chamo de "marcadores culturais", dizem ao leitor em que cultura a história se passa. ${ }^{8}$ (NORD, 1994, p. 553)

As referências culturais podem ser definidas, portanto, como: “os elementos do discurso que, por fazerem referência a particularidades da cultura de origem, ou não são entendidos em absoluto, ou o são de forma parcial, ou são entendidos de forma diferente pelos membros da cultura receptora” (MAYORAL, 1994, p. 76) ${ }^{9}$. Esse conceito pode ser relacionado com os conceitos de domesticação e estrangeirização propostos por Venuti (1995) - ou seja, respectivamente, quando se busca aproximar um conteúdo da cultura de chegada, ou quando se busca manter as marcas e peculiaridades da cultura de partida. Desse modo, no caso da estrangeirização, ao se preservar uma dada referência cultural, essa representará um elemento estrangeiro que tenderá a ser evidente à percepção do leitor da cultura receptora.

Assim, na localização, compreendem-se os marcadores culturais como elementos de uma obra que são manipulados pelo tradutor e cuja função é fazer com que os leitores se identifiquem diretamente com o texto, aproximando-os da cultura de chegada, ou que tenham uma relativa sensação de estranhamento em relação a esse texto, levando-os para mais perto da cultura de partida.

\section{Terminologia de análise}

A terminologia adotada para esta análise provém de Molina e Hurtado (2002, p. 509-511), que realizaram uma revisão terminológica e conceitual exaustiva das técnicas de tradução compiladas por Vinay e Darbelnet’s (1958), Vázquez Ayora (1977), Newmark (1988) e Delisle (1993), possibilitando uma perspectiva de análise funcional e dinâmica.

\footnotetext{
8 "In order to give the recipient a clue, the "text world" can be marked as belonging to a particular culture, either by means of explicit references to a specific model of reality (e. g. "wherever you go on the English coast”) or by means of implicit references to actions, attitudes, forms of behaviour or elements which are conventionally associated with specific models of reality (e. g. a proper name like Bill pointing to an anglophone text world). These explicit or implicit references, which I would like to call “culture-markers”, tell the reader in which culture the story is set.” (NORD, 1994, p. 553)

9 “(...) los elementos del discurso que por hacer referencia a particularidades de la cultura origen no son entendidos en absoluto o son entendidos de forma parcial o son entendidos de forma diferente por los miembros de la cultura término” (MAYORAL, 1994, p. 76)
} 
1. Adaptação: quando se substitui um elemento da cultura do texto de partida por um elemento da cultura receptora.

2. Amplificação: quando se adiciona elementos que não aparecem no texto de partida.

3. Empréstimo: quando se toma uma palavra ou expressão diretamente de outro idioma.

4. Calque: quando se traduz literalmente uma palavra ou expressão estrangeira.

5. Compensação: quando se introduz uma informação ou efeito estilístico do texto de partida em outra parte do texto de chegada por não se poder replicá-lo no mesmo lugar em que ocorre no texto de partida.

6. Descrição: quando se substitui um termo ou expressão pela descrição de sua forma ou função.

7. Criação discursiva: quando há o estabelecimento de uma equivalência temporária cuja apreensão é totalmente imprevisível fora de seu próprio contexto.

8. Equivalente estabelecido: quando se utilizar um termo ou expressão reconhecidos como equivalentes na língua de chegada.

9. Generalização: quando se utiliza um termo mais genérico ou neutro.

10. Amplificação linguística: quando se adiciona elementos lingüísticos.

11. Compressão lingüística: quando se sintetizam elementos linguísticos no texto de chegada.

12. Tradução literal: quando se traduz uma palavra ou expressão palavra por palavra.

13. Modulação: quando se altera o ponto de vista, foco ou categoria cognitiva em relação ao que se tem no texto de partida.

14. Particularização: quando se emprega um termo mais específico ou concreto.

15. Redução: quando se suprime uma informação do texto de partida no texto de chegada.

16. Substituição (lingüística, paralinguística): quando se substitui elementos linguísticos por paralinguísticos (entoação, gestual), ou o contrário.

17. Transposição: quando se altera uma categoria gramatical.

18. Variação: quando se modifica elementos linguísticos ou paralinguísticos (entoação, gestual) que afetem aspectos da variação lingüística: alteração do tom do texto, seu estilo, dialeto social ou geográfico, etc.

Tabela 1 - Descrição das técnicas de tradução

Essa terminologia foi utilizada aqui em combinação com os conceitos de “domesticação” e "estrangeirização”. Assim, examinar-se-á quais técnicas de tradução possuem maior caráter "domesticador" ou "estrangeirizador” nas traduções de fãs do jogo Chrono Trigger. Devido ao fato de que a proposta de Venuti é direcionada para a realidade anglófona e que sua descrição encontra-se dispersa ao longo de seu livro The translator's invisibility: a history of translation (1995), a adoção de alguns critérios analíticos foi necessária. Assim, são utilizados os seguintes critérios para definir operacionalmente "domesticação” e "estrangeirização":

1. Domesticação -

a) 1a: modificação de elementos linguístico-textuais com o objetivo de neutralizar ou suprimir palavras, letras e expressões estrangeiras;

b) 1b: tradução-adaptação que visa produzir um não-estranhamento linguístico-textual no leitor brasileiro;

c) 1c: utilização de palavras, metáforas, expressões ou jogos de palavras culturalmente significativos e característicos do português brasileiro. 
2. Estrangeirização -

a) 2a: preservação de palavras, letras ou traços linguístico-textuais que possam causar estranhamento ao leitor brasileiro;

b) 2b: utilização de expressões estrangeiras ou de um discurso menos usual na língua de chegada que produzam algum estranhamento linguístico-textual no leitor brasileiro;

c) 2c: utilização de construções sintáticas ou morfológicas que desviam do português brasileiro padrão.

O propósito dessa classificação, em conjunto com o uso das técnicas de Molina e Hurtado, é observar a intensidade com que os fenômenos de "domesticação” e “estrangeirização” aparecem nas traduções de fãs. Os elementos que se encaixam em 1a e 2a, portanto, representam os aspectos mais brandos de ambos os processos, pois o tradutor apenas mantém ou suprime/neutraliza determinados itens linguístico-textuais. Já as ações expressas em $1 \mathrm{~b}$ e $2 \mathrm{~b}$ envolvem um trabalho mais ativo do tradutor, pois esse precisa reconstruir o discurso para domesticá-lo, ou ressaltar nele aspectos estrangeiros. Por fim, os items 1c e 2c representam os casos em que a domesticação incorpora elementos típicos da cultura de recepção ou se desvia abertamente dos padrões gramaticais e culturais da língua de chegada.

\section{Análise}

Os itens analisados nesta seção incluem nomes de personagens principais e secundários, de “personagens de cenário” e nomes de inimigos. A escolha pela análise de nomes baseou-se na dependência que eles tem em relação às cultura das línguas de chegada e partida, pois as suas manutenção ou adaptação representam, invariavelmente, as abordagens por trás das escolhas realizadas pelos fãs-tradutores.

\section{Nomes de personagens principais, secundários e “de cenário”}

No mundo real, nomes próprios podem ser não-descritivos, porém dificilmente são também não-informativos. Quando se é familiar com uma língua, um nome próprio pode nos indicar o gênero de uma pessoa, seu local de origem ou o referente do nome (caso trate-se, por exemplo, de um animal de estimação). A nomeação de personagens constitui, portanto, uma área de interesse para os Estudos da Tradução, pois os nomes têm a capacidade de sugerir associações bastante peculiares aos leitores, especialmente quando utilizados como recurso para o humor ou a ironia.

No caso de Chrono Trigger, diversos nomes fictícios apresentam combinações de caracteres incomuns. Isso implica na possibilidade de liberdade de escolha para os fãs-tradutores, pois podem optar por alterar esses nomes ou por manter suas características exóticas. A tabela a seguir apresenta o nome dos personagens principais que podem ser controlados pelos usuários: 


\begin{tabular}{|c|c|c|c|c|c|}
\hline & Texto de partida & $\begin{array}{c}\text { Tradução de } \\
\text { fãs }\end{array}$ & $\begin{array}{l}\text { Técnicas e estraté- } \\
\text { gias de tradução }\end{array}$ & $\begin{array}{l}\text { Tradução } \\
\text { de fãs }\end{array}$ & $\begin{array}{c}\text { Técnicas estratégia } \\
\text { de tradução }\end{array}$ \\
\hline & Nintendo (1995) & CBT & & Ips Center & \\
\hline 1 & Crono & Crono & $\begin{array}{l}\text { Empréstimo } \\
\text { +Estrang. 2.a }\end{array}$ & Crono & $\begin{array}{l}\text { Empréstimo } \\
\text { +Estrang. 2.a }\end{array}$ \\
\hline 2 & Marle & Marle & $\begin{array}{l}\text { Empréstimo } \\
\text { +Estrang. 2.a }\end{array}$ & Marle & $\begin{array}{l}\text { Empréstimo } \\
+ \text { Estrang. 2.a }\end{array}$ \\
\hline 3 & Lucca & Lucca & $\begin{array}{l}\text { Empréstimo } \\
+ \text { Estrang. 2.a }\end{array}$ & Lucca & $\begin{array}{l}\text { Empréstimo } \\
+ \text { Estrang. 2.a }\end{array}$ \\
\hline 4 & Ayla & Ayla & $\begin{array}{l}\text { Empréstimo } \\
+ \text { Estrang. 2.a }\end{array}$ & Ayla & $\begin{array}{l}\text { Empréstimo } \\
+ \text { Estrang. 2.a }\end{array}$ \\
\hline 5 & Robo & Robo & $\begin{array}{l}\text { Empréstimo } \\
+ \text { Estrang. 2.a }\end{array}$ & Robo & $\begin{array}{l}\text { Empréstimo } \\
\text { +Estrang. 2.a }\end{array}$ \\
\hline 6 & Magus & Magus & $\begin{array}{l}\text { Empréstimo } \\
+ \text { +Estrang. 2.a }\end{array}$ & Magus & $\begin{array}{l}\text { Empréstimo } \\
+ \text { Estrang. 2.a }\end{array}$ \\
\hline 7 & Frog & Frog & $\begin{array}{l}\text { Empréstimo } \\
+ \text { Estrang. 2.a }\end{array}$ & Frog & $\begin{array}{l}\text { Empréstimo } \\
\text { +Estrang. 2.a }\end{array}$ \\
\hline
\end{tabular}

Tabela 2 - Os Protagonistas de Chrono Trigger

Como pode ser percebido, tanto o grupo CBT quanto o Ips Center não modificam os nomes dos protagonistas, até mesmo no caso de Frog, que possui um equivalente em português facilmente identificável ("sapo"). Talvez pelo fato de o jogo ser bastante conhecido e ter uma base considerável de fãs os tradutores se mostraram conservadores em relação à alteração desses nomes. O resultado é um conjunto de nomes claramente exótico, que evoca no jogador brasileiro um estranhamento inicial e a percepção da obra como um produto estrangeiro.

O mesmo não se aplica, no entanto, aos personagens secundários que participam do desenvolvimento da narrativa, também conhecidos como NPCs ${ }^{10}$ :

\begin{tabular}{|c|c|c|c|c|c|}
\hline & Texto de partida & $\begin{array}{c}\text { Tradução } \\
\text { de fãs }\end{array}$ & $\begin{array}{c}\text { Técnicas e estratégias } \\
\text { de tradução }\end{array}$ & $\begin{array}{c}\text { Tradução de } \\
\text { fãs }\end{array}$ & $\begin{array}{c}\text { Técnicas e estraté- } \\
\text { gias de tradução }\end{array}$ \\
\hline & Nintendo (1995) & CBT & & Ips Center & \\
\hline 1 & Azala & Azala & $\begin{array}{l}\text { Empréstimo } \\
\text { +Estrang. 2.a }\end{array}$ & Azala & $\begin{array}{l}\text { Empréstimo } \\
\text { +Estrang. 2.a }\end{array}$ \\
\hline 2 & Belthasar & Baltasar & $\begin{array}{l}\text { Variação } \\
\text { +Domestic. 1.a }\end{array}$ & Belthasar & $\begin{array}{l}\text { Empréstimo } \\
\text { +Estrang. 2.a }\end{array}$ \\
\hline 3 & Cyrus & Cirus & $\begin{array}{l}\text { Variação } \\
\text { +Domestic. 1.a }\end{array}$ & Cyrus & $\begin{array}{l}\text { Empréstimo } \\
+ \text { Estrang. 2.a }\end{array}$ \\
\hline 4 & Dalton & Dalton & $\begin{array}{l}\text { Empréstimo } \\
\text { +Estrang. 2.a }\end{array}$ & Dalton & $\begin{array}{l}\text { Empréstimo } \\
\text { +Estrang. 2.a }\end{array}$ \\
\hline 5 & Fiona & Fiona & $\begin{array}{l}\text { Empréstimo } \\
\text { +Estrang. 2.a }\end{array}$ & Fiona & $\begin{array}{l}\text { Empréstimo } \\
\text { +Estrang. 2.a }\end{array}$ \\
\hline 6 & Flea & Flea & \begin{tabular}{|l|}
$\begin{array}{l}\text { Empréstimo } \\
\text { +Estrang. 2.a }\end{array}$ \\
\end{tabular} & Flea & \begin{tabular}{|l|}
$\begin{array}{l}\text { Empréstimo } \\
+ \text { Estrang. 2.a }\end{array}$ \\
\end{tabular} \\
\hline 7 & Gaspar & Gaspar & Empréstimo & Gaspar & Empréstimo \\
\hline
\end{tabular}

${ }^{10}$ Non-playable-characters, ou seja, “personagens não-controláveis” 


\begin{tabular}{|c|c|c|c|c|c|}
\hline & & & +Estrang. 2.a & & +Estrang. 2.a \\
\hline 8 & Janus & Ianus & $\begin{array}{l}\text { Variação } \\
+ \text { Domestic. 1.a } \\
\end{array}$ & Janus & $\begin{array}{l}\text { Empréstimo } \\
\text { +Estrang. 2.a }\end{array}$ \\
\hline 9 & Johnny & Billie & $\begin{array}{l}\text { Variação } \\
\text { +Estrang. 2.b }\end{array}$ & Johnny & $\begin{array}{l}\text { Empréstimo } \\
\text { +Estrang. 2.a }\end{array}$ \\
\hline 10 & Kino & Quino & $\begin{array}{l}\text { Variação } \\
\text { +Domestic. 1.a }\end{array}$ & Kino & $\begin{array}{l}\text { Empréstimo } \\
+ \text { Estrang. 2.a }\end{array}$ \\
\hline 11 & Melchior & Belquior & $\begin{array}{l}\text { Variação } \\
\text { +Domestic. 1.a } \\
\end{array}$ & Melchior & $\begin{array}{l}\text { Empréstimo } \\
\text { +Estrang. 2.a }\end{array}$ \\
\hline 12 & Ozzie & Ossie & $\begin{array}{l}\text { Variação } \\
\text { +Domestic. 1.a }\end{array}$ & Ozzie & $\begin{array}{l}\text { Empréstimo } \\
\text { +Estrang. 2.a }\end{array}$ \\
\hline 13 & Queen Leene & $\begin{array}{l}\text { Rainha } \\
\text { Lena }\end{array}$ & $\begin{array}{l}\text { Transliteração e Varia- } \\
\text { ção } \\
\text { +Domestic. 1.a e 1.b }\end{array}$ & Rainha Leene & $\begin{array}{l}\text { Transliteração e } \\
\text { Empréstimo } \\
\text { + Estrang. 2.a }\end{array}$ \\
\hline 14 & Queen Zeal & $\begin{array}{l}\text { Rainha } \\
\text { Seal }\end{array}$ & $\begin{array}{l}\text { Transliteração e Varia- } \\
\text { ção } \\
\text { +Domestic. 1.a e 1.b }\end{array}$ & Rainha Zeal & $\begin{array}{l}\text { Transliteração e } \\
\text { Empréstimo } \\
+ \text { Estrang. 2.a }\end{array}$ \\
\hline 15 & Schala & Sara & $\begin{array}{l}\text { Variação } \\
\text { +Domestic. 1.a }\end{array}$ & Schala & $\begin{array}{l}\text { Empréstimo } \\
+ \text { Estrangeirização }\end{array}$ \\
\hline 16 & Slash & Slash & $\begin{array}{l}\text { Empréstimo } \\
\text { +Estrang. 2.a } \\
\end{array}$ & Slash & $\begin{array}{l}\text { Empréstimo } \\
+ \text { Estrang. 2.a }\end{array}$ \\
\hline 17 & Spekkio & Espequio & $\begin{array}{l}\text { Variação } \\
\text { +Domestic. 1.a }\end{array}$ & Spekkio & $\begin{array}{l}\text { Empréstimo } \\
+ \text { Estrang. 2.a }\end{array}$ \\
\hline 18 & Tata & Tata & $\begin{array}{l}\text { Empréstimo } \\
\text { +Estrang. 2.a }\end{array}$ & Tata & $\begin{array}{l}\text { Empréstimo } \\
+ \text { Estrang. 2.a }\end{array}$ \\
\hline 19 & Toma & Toma & $\begin{array}{l}\text { Empréstimo } \\
+ \text { Estrang. 2.a }\end{array}$ & Toma & $\begin{array}{l}\text { Empréstimo } \\
\text { +Estrang. 2.a }\end{array}$ \\
\hline
\end{tabular}

Tabela 3 - Personagens secundários de Chrono Trigger

No caso dos nomes Baltasar, Espequio, Ossie, Quino e Sara, a tradução do grupo CBT utiliza por diversas vezes a técnica da "variação", em sua maior parte empregando uma estratégia domesticadora, no sentido de substituir letras ou combinações de letras estrangeiras, além de aproximar alguns nomes da cultura brasileira, como o exemplo 15 em que "Schala" torna-se "Sara". No total, 55\% dos nomes sofrem algum tipo de modificação em sua estrutura, sendo domesticados para a cultura brasileira.

Essa domesticação inclui, predominantemente, a modificação de caracteres nos exemplos 3, 8, 10,12, 13, 14, 15 e 17. Apenas nos exemplos 13 e 14 houve também a supressão de uma palavra estrangeira. Na tradução do Ips Center, por outro lado, os nomes não sofrem alterações, excetuando-se as rainhas. Os níveis de “estrangeirização” e “domesticação” nestes exemplos manteve-se brando sendo mínimas as alterações realizadas.

Há, no entanto, uma terceira classe de personagens, os quais não são controláveis e também não participam diretamente do desenvolvimento da narrativa, nomeados aqui como "personagens de cenário". Estes personagens aparecem como elementos estáticos num local, pois a interação do jogador com eles produzirá sempre a mesma sentença ou padrão de ação. Muitos não possuem nome, produzindo apenas uma ou mais sentenças que servem para contextualizar o jogador dentro da narrativa, dar uma pista sobre algum segredo ou explicar alguma mecânica do jogo. 
Outros, porém, fazem parte das cenas nas quais o jogador está propriamente inserido, como é o caso dos quatro corredores que competem no festival da Praça Leene:

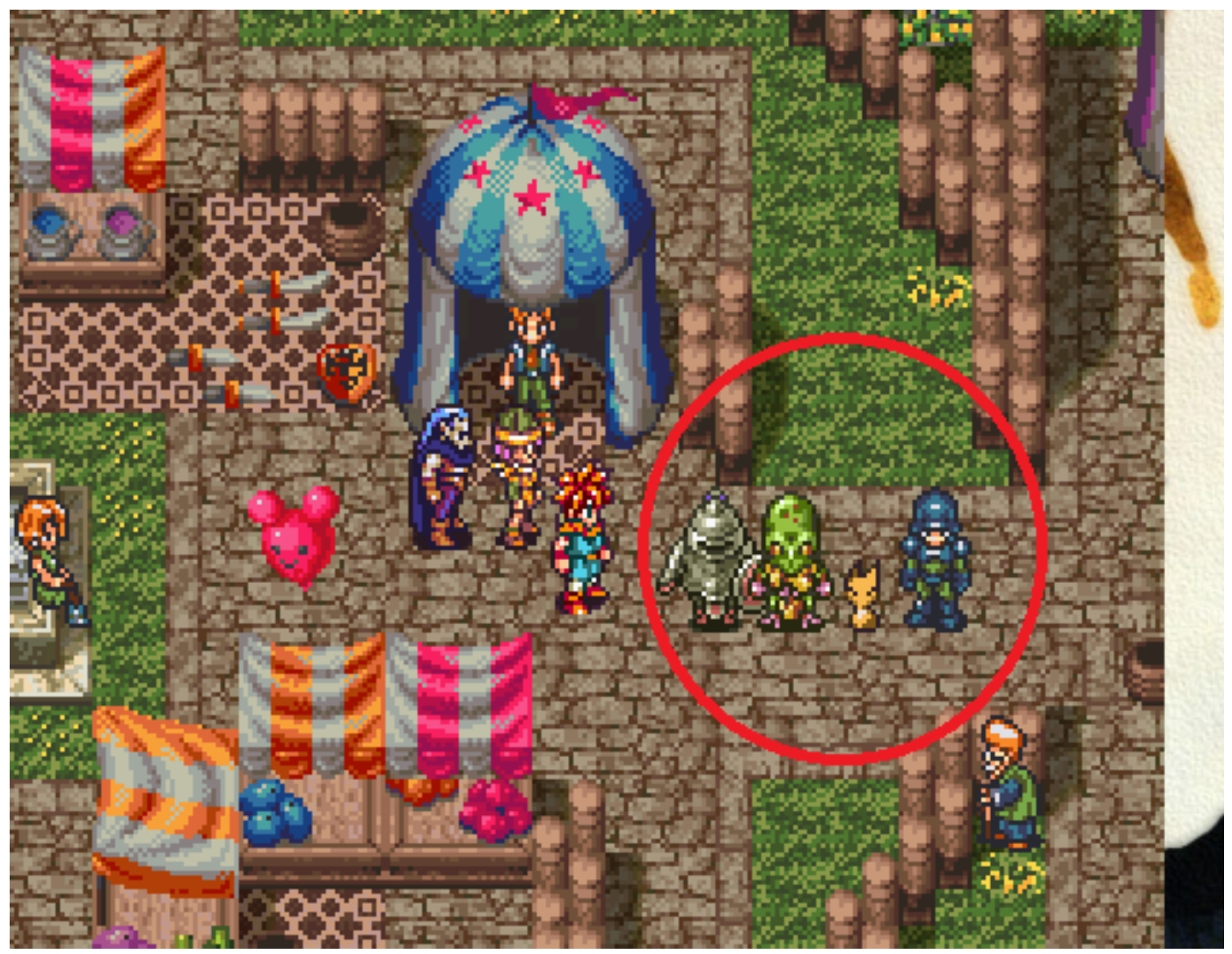

Figura 1 - Os corredores da Praça Leene

Alguns dos nomes desses personagens foram adaptados de modo que os jogadores brasileiros facilmente identifiquem suas referências culturais, pois o grupo CBT utiliza dois nomes bastante conhecidos: ET de Varginha (referência ao mito local de um ser extraterrestre que teria aparecido na cidade de Varginha em Minas Gerais) e Seu Madruga (referência a um personagem da série mexicana de televisão Chaves, dublada e exibida nos anos 90 pelo canal SBT):

\begin{tabular}{l|l|l|l|l|l} 
& Texto de partida & Tradução de fãs & $\begin{array}{l}\text { Técnicas e es- } \\
\text { tratégia }\end{array}$ & $\begin{array}{c}\text { Tradução de } \\
\text { fãs }\end{array}$ & $\begin{array}{l}\text { Técnicas e estra- } \\
\text { tégia }\end{array}$ \\
\hline & Nintendo (1995) & \multicolumn{1}{|c}{ CBT } & & \multicolumn{1}{|c}{ Ips Center } & \\
\hline 1 & A. Steel Runner! & A. O Gordinho & $\begin{array}{l}\text { Adaptação } \\
\text { +Domestic. 1.c }\end{array}$ & $\begin{array}{l}\text { A. Corredor de } \\
\text { Aço }\end{array}$ & $\begin{array}{l}\text { Transliteração } \\
\text { +Domestic 1.b }\end{array}$ \\
\hline 2 & B. Green Ambler! & B. ET de Varginha & $\begin{array}{l}\text { Adaptação } \\
\text { +Domestic 1.c }\end{array}$ & $\begin{array}{l}\text { B. Viajante } \\
\text { Verde }\end{array}$ & $\begin{array}{l}\text { Adaptação } \\
\text { +Estrang. 2.a }\end{array}$ \\
\hline 3 & C. Catalack! & C. Gatuno & $\begin{array}{l}\text { Variação } \\
\text { +Domestic 1.b }\end{array}$ & C. Gatalack & $\begin{array}{l}\text { Variação } \\
\text { +Estrang. 2.a }\end{array}$ \\
\hline 4 & D. G. I. Jogger! & D. Seu Madruga & $\begin{array}{l}\text { Adaptação } \\
\text { +Domestic 1.c }\end{array}$ & $\begin{array}{l}\text { D. General } \\
\text { Lento }\end{array}$ & $\begin{array}{l}\text { Criação discursiva } \\
\text { +Domestic 1.b }\end{array}$
\end{tabular}

Tabela 4 - Personagens de cenário 
O Ips Center, no entanto, mantém certa reserva em relação a essas adaptações com nomes, preferindo a transliteração do exemplo 1 e uma criação discursiva sem alusões no exemplo 4. Nos exemplos 2 e 3, porém, suas traduções se aproximam do texto estrangeiro ao produzir dois nomes que não são facilmente assimiláveis pelo jogador brasileiro.

Assim, as traduções de fãs podem seguir caminhos bastante diferentes. Algumas podem utilizar mais adaptações culturais, até mesmo transcriando nomes próprios, enquanto outras podem considerar a manutenção de alguns elementos estrangeiros como uma forma de preservar a sensação proporcionada pelo jogo original.

Parte dessas opções se revela no discurso de Lynx, tradutor do Ips Center, em um arquivo de texto comprimido em conjunto com o arquivo IPS ${ }^{11}$, no qual o fã responsável pela segunda tradução brasileira de Chrono Trigger revela parte de suas motivações:

De cara, fiquei muito contente por ver um jogo que eu gostava muito finalmente na minha língua, mas, por outro lado, um tanto decepcionado com as trocas de nomes proporcionadas pela antiga tradução. Ver a minha querida Schala como Sara, Melchior como Belquior e tantas outras trocas acabaram por "estragar" o que poderia ser uma excelente tradução. E aí eu pensava comigo: "Puxa, se eu soubesse como traduzir, poderia fazer melhor". (Linx, 2004, p.1) ${ }^{12}$

\section{Nomes de inimigos}

Um jogo só prende a atenção de um jogador na medida em que apresenta algum desafio, ou desafios, a ser superado. Os inimigos costumam fazer parte desse processo de superação de desafios que o jogador vai acumulando ao longo de sua jornada. Em Chrono Trigger há dois tipos diferentes de inimigos: dinâmicos e estáticos.

Inimigos dinâmicos interagem verbalmente com os avatares do jogador. Inimigos estáticos, por outro lado, são uma espécie de complemento do ambiente, pois apenas atacam ou são atacados pelos personagens, sem que exista uma razão mais profunda, por assim dizer, para o conflito. Há exceções, como o caso de um inimigo do tipo "Nagaette" (uma cobra humanoide) que está disfarçada como uma freira em uma catedral, e por isso interage primeiramente como um personagem de cenário. A maior parte dos inimigos, porém, segue o padrão de expressar poucas palavras ou não se pronunciar.

No caso dos nomes de inimigos estáticos analisados, houve uma taxa de domesticação e estrangeirização semelhante nas duas traduções, talvez porque muitos desses nomes envolvam uma combinação humorística de palavras, como se observa nas tabelas a seguir:

\footnotetext{
${ }^{11}$ Arquivo através do qual uma tradução pode ser aplicada em um jogo.

${ }^{12}$ Arquivos de texto e tradução disponíveis em:

http://www.brgames.org/download.php?ipstraduzido=317
} 


\begin{tabular}{|c|c|c|c|c|c|}
\hline & $\begin{array}{l}\text { Texto de } \\
\text { partida }\end{array}$ & \begin{tabular}{|} 
Tradução de \\
fãs
\end{tabular} & $\begin{array}{l}\text { Técnicas e estraté- } \\
\text { gias de tradução }\end{array}$ & $\begin{array}{l}\text { Tradução de } \\
\text { fãs }\end{array}$ & $\begin{array}{c}\text { Técnicas e estraté- } \\
\text { gias de tradução }\end{array}$ \\
\hline & $\begin{array}{c}\text { Nintendo } \\
\text { (1995) }\end{array}$ & CBT & & Ips Center & \\
\hline 1 & $\mathrm{Nu}$ & $\mathrm{Nu}$ & $\begin{array}{l}\text { Empréstimo } \\
\text { +Estrang. 2.a }\end{array}$ & $\mathrm{Nu}$ & $\begin{array}{l}\text { Empréstimo } \\
+ \text { Estrang. 2.a }\end{array}$ \\
\hline 2 & Terrasaur & Terassauro & $\begin{array}{l}\text { Calque } \\
\text { + Domestic 1.a }\end{array}$ & Megassauro & $\begin{array}{l}\text { Variação } \\
\text { + Domestic 1.a }\end{array}$ \\
\hline 3 & Bellbird & Sinaleiro & $\begin{array}{l}\text { Criação discursiva } \\
\text { + Domestic 1.c }\end{array}$ & Águia sino & $\begin{array}{l}\text { Transliteração } \\
\text { + Estrang. 2.a }\end{array}$ \\
\hline 4 & Mammon M & M.Mamon & $\begin{array}{l}\text { Variação } \\
+ \text { Estrang 2.a }\end{array}$ & M.Mamon & $\begin{array}{l}\text { Variação } \\
+ \text { Estrang 2.a }\end{array}$ \\
\hline 5 & Blue Imp & Diabo Azul & $\begin{array}{l}\text { Transliteração } \\
+ \text { Domestic 2.b }\end{array}$ & Duende azul & $\begin{array}{l}\text { Transliteração } \\
+ \text { Domestic 1.b }\end{array}$ \\
\hline 6 & Green Imp & Diabo Verde & $\begin{array}{l}\text { Transliteração } \\
\text { + Domestic 2.b }\end{array}$ & Duende verde & $\begin{array}{l}\text { Transliteração } \\
\text { + Domestic 1.b }\end{array}$ \\
\hline 7 & Stone Imp & Diabo Pedra & $\begin{array}{l}\text { Transliteração } \\
+ \text { Domestic 1.b }\end{array}$ & Duende mini & $\begin{array}{l}\text { Adaptação } \\
\text { + Domestic 1.b }\end{array}$ \\
\hline 8 & Mud Imp & Diabo Lama & $\begin{array}{l}\text { Transliteração } \\
\text { + Domestic 1.b }\end{array}$ & Duende sujo & $\begin{array}{l}\text { Adaptação } \\
+ \text { Domestic 1.b }\end{array}$ \\
\hline 9 & Roly & Rolo & $\begin{array}{l}\text { Adaptação } \\
\text { + Domestic 1.b }\end{array}$ & Rolo & $\begin{array}{l}\text { Adaptação } \\
\text { + Domestic 1.b }\end{array}$ \\
\hline 10 & Rolypoly & Rolopolia & $\begin{array}{l}\text { Adaptação } \\
+ \text { Estrang 2.a }\end{array}$ & Rolante & $\begin{array}{l}\text { Adaptação } \\
+ \text { Domestic 1.b }\end{array}$ \\
\hline 11 & Gnasher & Cobra & $\begin{array}{l}\text { Adaptação } \\
+ \text { Domestic 1.b }\end{array}$ & Rangedor & $\begin{array}{l}\text { Adaptação } \\
+ \text { Estrang 2.b }\end{array}$ \\
\hline 12 & Gnawer & Roedor & $\begin{array}{l}\text { Adaptação } \\
\text { + Domestic 1.b }\end{array}$ & Roedor & $\begin{array}{l}\text { Adaptação } \\
\text { + Domestic 1.b }\end{array}$ \\
\hline 13 & Nagaette & Nagaete & $\begin{array}{l}\text { Variação } \\
\text { +Estrang 2.a }\end{array}$ & Naga & $\begin{array}{l}\text { Adaptação } \\
+ \text { Domestic 1.b }\end{array}$ \\
\hline 15 & Octopod & Octópode & $\begin{array}{l}\text { Transliteração } \\
+ \text { Domestic 1.b }\end{array}$ & Octópode & $\begin{array}{l}\text { Transliteração } \\
\text { + Domestic 1.a }\end{array}$ \\
\hline
\end{tabular}

Tabela 5 - Inimigos. 1

É importante destacar que algumas das escolhas lexicais realizadas pelos tradutores do grupo CBT e do IPS Center se afastam consideravelmente do texto de partida, ou o recriam de modo inusitado. O exemplo 3 da CBT, "Sinaleiro", parece ser inspirado na tradução da palavra bell ('sino'), enquanto o exemplo 2 do IPS Center utiliza o prefixo "mega" para enfatizar o tamanho do inimigo.

Em outros casos, como os exemplos 8 e 11 do IPS Center, prevalece a interpretação do tradutor sobre o visual ou sobre o comportamento gráfico dos personagens uma vez que o "duende sujo" tem uma cor de terra que pode ser associada à sujeira, e o "rangedor” é, na verdade, uma cobra que realiza uma espécie de vibração ao atacar. Algumas das traduções também utilizam uma linguagem bastante coloquial, como os exemplos 18, 19 e 24 da CBT: "papa mosca”, “ovo podre” e "acabado": 


\begin{tabular}{|c|c|c|c|c|c|}
\hline 16 & Octoblush & Octobino & \begin{tabular}{|l} 
Variação \\
+ Domestic 2.a
\end{tabular} & Octorubro & \begin{tabular}{|l} 
Variação \\
+Estrang 2.a
\end{tabular} \\
\hline 17 & Zeal & Seal & \begin{tabular}{|l|} 
Variação \\
+ Domestic 1.a \\
\end{tabular} & Zeal & $\begin{array}{l}\text { Empréstimo } \\
+ \text { + Estrang 2.a }\end{array}$ \\
\hline 18 & Fly Trap & Papa Mosca & $\begin{array}{l}\text { Adaptação } \\
\text { + Domestic 1.c }\end{array}$ & Papa mosca & $\begin{array}{l}\text { Adaptação } \\
+ \text { Domestic 1.c }\end{array}$ \\
\hline 19 & Meat eater & Carnívoro & $\begin{array}{l}\text { Particularização } \\
\text { + Domestic 2.a }\end{array}$ & Carnívoro & $\begin{array}{l}\text { Particularização } \\
\text { + Domestic 2.a }\end{array}$ \\
\hline 20 & Man eater & Canibal & $\begin{array}{l}\text { Particularização } \\
\text { + Domestic 2.a } \\
\end{array}$ & Canibal & $\begin{array}{l}\text { Particularização } \\
\text { + Domestic 2.a } \\
\end{array}$ \\
\hline 21 & Edger & Ovo Podre & \begin{tabular}{|l|} 
Adaptação \\
+ Domestic 1.c
\end{tabular} & Ovus & \begin{tabular}{|l|} 
Criação discursiva \\
+ Estrang 2.b
\end{tabular} \\
\hline 22 & Defunct & Defunto & $\begin{array}{l}\text { Transliteração } \\
\text { + Domestic 1.b }\end{array}$ & Morto & $\begin{array}{l}\text { Generalização } \\
\text { + Domestic 1.b }\end{array}$ \\
\hline 23 & Departed & Funério & $\begin{array}{l}\text { Criação discursiva } \\
\text { + Domestic 1.a } \\
\end{array}$ & Finado & $\begin{array}{l}\text { Generalização } \\
\text { + Domestic 1.b }\end{array}$ \\
\hline 24 & Decedent & Acabado & \begin{tabular}{|l|} 
Adaptação \\
+ Domestic 1.c
\end{tabular} & Decadente & $\begin{array}{l}\text { Adaptação } \\
+ \text { Domestic 1.b }\end{array}$ \\
\hline 25 & Macabre & Macabro & $\begin{array}{l}\text { Transliteração } \\
\text { + Domestic 1.b } \\
\end{array}$ & Macabro & $\begin{array}{l}\text { Transliteração } \\
\text { + Domestic 1.b }\end{array}$ \\
\hline 26 & Reaper & Ceifador & $\begin{array}{l}\text { Transliteração } \\
\text { + Domestic 1.b }\end{array}$ & Ceifador & $\begin{array}{l}\text { Transliteração } \\
\text { + Domestic 1.b }\end{array}$ \\
\hline 27 & Guard & Guarda & $\begin{array}{l}\text { Transliteração } \\
\text { + Domestic 1.b }\end{array}$ & Guarda & $\begin{array}{l}\text { Transliteração } \\
\text { + Domestic 1.b }\end{array}$ \\
\hline 28 & Sentry & Sentinela & $\begin{array}{l}\text { Transliteração } \\
+ \text { Domestic 1.b } \\
\end{array}$ & Sentinela & $\begin{array}{l}\text { Transliteração } \\
\text { + Domestic 1.b }\end{array}$ \\
\hline 29 & Outlaw & Bandido & $\begin{array}{l}\text { Particularização } \\
\text { + Domestic 1.b }\end{array}$ & Bandido & $\begin{array}{l}\text { Particularização } \\
\text { + Domestic 1.b }\end{array}$ \\
\hline 30 & Giga Mutant & Giga Mutant & $\begin{array}{l}\text { Empréstimo } \\
\text { +Estrang 2.a }\end{array}$ & Giga Mutante & $\begin{array}{l}\text { Variação } \\
\text { +Domestic 1.a }\end{array}$ \\
\hline 31 & $\begin{array}{l}\text { Terra Mu- } \\
\text { tant }\end{array}$ & Terra Mutant & $\begin{array}{l}\text { Empréstimo } \\
\text { +Estrang 2.a }\end{array}$ & Terra Mutante & \begin{tabular}{|l|} 
Variação \\
+Domestic 1.a
\end{tabular} \\
\hline 32 & Juggler & Ilusionista & $\begin{array}{l}\text { Adaptação } \\
+ \text { Domestic 1.b }\end{array}$ & Ilusionista & $\begin{array}{l}\text { Adaptação } \\
+ \text { Domestic 1.b }\end{array}$ \\
\hline 33 & Boss Orb & Orb Chefe & \begin{tabular}{|l|} 
Transliteração e \\
Empréstimo \\
+Estrang 2.a \\
\end{tabular} & Chefe Orbe & $\begin{array}{l}\text { Transliteração e Va- } \\
\text { riação } \\
\text { + Domestic 1.a }\end{array}$ \\
\hline 34 & Jinn Bottle & Garrafa Mgc & $\begin{array}{l}\text { Transliteração e } \\
\text { Compressáo linguís- } \\
\text { tica } \\
\text { + Domestic 1.b } \\
\end{array}$ & JinnMaligno & $\begin{array}{l}\text { Adaptação } \\
\text { +Estrang 2.b }\end{array}$ \\
\hline 35 & \begin{tabular}{|l} 
Lavos \\
Spawn
\end{tabular} & Ova Lavos & \begin{tabular}{|l} 
Transliteração \\
+ Estrang 2.a
\end{tabular} & Ova Lavos & \begin{tabular}{|l}
$\begin{array}{l}\text { Transliteração } \\
\text { + Estrang 2.a }\end{array}$ \\
\end{tabular} \\
\hline
\end{tabular}

Tabela 6 - Inimigos. 2

No caso do grupo CBT, cerca de $26 \%$ das traduções referidas são estrangeirizadoras em algum aspecto, como nos exemplos 4, 10, 13, 30, 31 e 35, em que ocorre a preservação de palavras ou letras do vocábulo estrangeiro. A tradução do Ips Center, por sua vez, conta com $29 \%$ de elementos típicos da cultura estrangeira no recorte analisado. Há uma maior tendência, nessa tradução, de se deixar marcas da cultura estrangeira nos nomes, como nos exemplos 11, 13, 21 e 34, em que se tem "JinnMaligno" e "Rangedor”. 
Em ambas as traduções, no entanto, predomina o processo de "domesticação”. O Ips Center utiliza essa estratégia em $71 \%$ das traduções, enquanto o grupo CBT o faz 74\% das vezes. Nesse aspecto, as duas traduções apresentam vocábulos como "Papa Moscas", “Octorubro" e "Funério”, pois o humor permite ao tradutor uma maior liberdade tradutória. Há ainda um processo de supressão das marcações estrangeiras, pois os tradutores do Ips Center adicionam uma letra ao exemplo 33, domesticando o "Chefe Orbe", e realizam o mesmo processo nos exemplos 30 e 31, transformando-os em "Giga mutante” e "Terra mutante”.

Os nomes de inimigos, desse modo, são predominantemente transformados de modo a se tornarem mais naturais para os jogadores brasileiros, o que faz com que a maior parte das classificações de domesticação seja do tipo 1b, sendo poucas as ocasiões em que a língua de partida é evidenciada. Esse procedimento se assemelha ao das traduções oficiais, pois o principal interesse do tradutor é fazer com que o leitor se mantenha entretido com o jogo.

\section{Conclusão}

A pesquisa realizada revelou que as duas traduções de fãs utilizam prioritariamente a estratégia da "domesticação", em consonância com as práticas de tradutores oficiais. O modelo de transcriação parece, então, uma proposta relevante para compreender o funcionamento da tradução de videogames, tanto as oficiais quanto aquelas realizadas por fãs, pois aponta que a principal estratégia utilizada na tradução de videogames é a adaptação do conteúdo para o local de destino, o que se conforma ao afirmado por Mangiron e O’Hagan (2006, p. 17-19). As escolhas lexicais dos fãs, por sua vez, indicam que há uma grande transcriação na tradução de diversos vocábulos, não sendo incomum que o nome de um inimigo seja adaptado para a cultura brasileira.

Dentre os resultados finais, no caso do grupo Ips Center, observou-se uma maior conservação de elementos do texto de partida apenas em casos específicos, como a nomeação de personagens principais e secundários, com uso prioritário da estratégia da “domesticação”. O grupo CBT, por sua vez, alternou entre a neutralização das características estrangeiras e a utilização de elementos domésticos de uma forma mais intensa, chegando a utilizar referências locais, e tornadas locais, como ao "ET de varginha" e ao personagem "Seu Madruga".

Rafael Müller Galhardi aterion@gmail.com Mestre em Tradução e Acessibilidade, Universidade Federal da Bahia 


\section{Referências bibliográficas}

DeLISLE, Jean. La traduction raisonnée. Manuel d'initiation à la traduction professionnelle de l'anglais vers le français. Ottawa: Presses de l'Université d'Ottawa, 1993.

DIETZ, Franz. Issues in Localizing Computer Games. In: Perspectives on Localization. Amsterdam e Philadelphia: John Benjamins, 2006.

FISH, Stanley Eugene. Is there a text in this class? The authority of interpretive communities. Cambridge, Ma: Harvard University Press, 1980.

Kersten, E. Gregory; Kersten, Mik; RAKOwsKi, M. Wojcieh. Software and Culture: Beyond the Internationalization of the Interface. In: Journal of Global Information Management (JGIM), v. 10, p. 86-101, 2002. Disponível em: $<$ http://users.jyu.fi/ japawlow/05_kersten_2002.pdf $>$ Acesso em 09/05/2012.

MANGIRON, Carmen; O'HAGAN, Minako. Game Localisation: Unleashing Imagination with Restricted Translation. In: Journal Of Specialised Translation, 6, 2006. Disponível em: <http://www.jostrans.org/issue06/art_ohagan.pdf> Acesso em: 20/03/2012.

MAyORAL, Roberto. La explicitacíon de información em la traducción intercultural. In: Estudis sobre la Traduccio. Castello: Publicacions de la Universitat Jaume I, 1994.

MolinA, Lucia; HurTAdo, Amparo. Translation techniques revisited: a dinamyc and functional approach. Meta, XLVII (4), p. 498-512, 2002.

Newmark, Peter. A Textbook of Translation. Oxford and New York: Pergamon, 1988.

NORD, Christiane. It's tea time in wonderland: cultural markers in fictional texts. Frankfurt: Peter Lang, 1994.

Pham, A. \& Sandell, S., 2003. In Germany, Video Games Showing Frontal Nudity Are OK, but Blood Is Verboten. Los Angeles Times. Disponível em: http://articles.latimes.com/2003/jun/09/business/fi-german9 Acesso em: 03 de janeiro de 2014.

VENUTI, Lawrence. The translator's invisibility: a history of translation. London: Routledge, 1995.

VERMEER, Hans. What does it mean to translate? In: Indian journal of applied linguistics, 13 (2), p. 25-33, 1987.

VÁZQUEZ-AYORA-Ayora, Gerardo. Introducción a la traductología. Washington: Georgetown University, 1977.

VinAy, Jean Paul \& DARBELnet, Jean. Stylistique comparée du français et de l'anglais. Didier: Georgetown University Press., 1977. 